\title{
Lidar monitoring of organic matter in the Pearl River estuary (withdrawal notice)
}

Peng Chen, Delu Pan, Chuanwen Hu, Jianyu Chen, Haiqing Huang

Peng Chen, Delu Pan, Chuanwen Hu, Jianyu Chen, Haiqing Huang, "Lidar monitoring of organic matter in the Pearl River estuary (withdrawal notice)," Proc. SPIE 9218, Earth Observing Systems XIX, 921810 (25 September 2014); doi: 10.1117/12.2060360

Event: SPIE Optical Engineering + Applications, 2014, San Diego, California, United States 


\section{Lidar monitoring of organic matter in the Pearl River Estuary (withdrawal notice)}

Proc. SPIE 9218, 921810 (2014); http://dx.doi.org/ 10.1117/12.2060360

Online Publication Date: 25 September 2014

Withdrawn from Publication: 2 October 2014

Conference Date: Sunday 18-20 August 2014

Conference Location: San Diego, California, United States

Conference Title:

Earth Observing Systems XIX

Conference Chair: James J. Butler, Xiaoxiong Xiong, Xingfa Gu

Peng Chen, Delu Pan

The Second Institute of Oceanography, SOA (China)

Chuanwen $\mathrm{Hu}$

The First Surveying and Mapping Institute of Zhejiang Province

Jianyu Chen, Haiqing Huang

The Second Institute of Oceanography, SOA (China)

This paper has been withdrawn by the publisher because it was not presented at the conference. 